\title{
Gastric mesh erosion after hiatoplasty for recurrent paraesophageal hernia
}

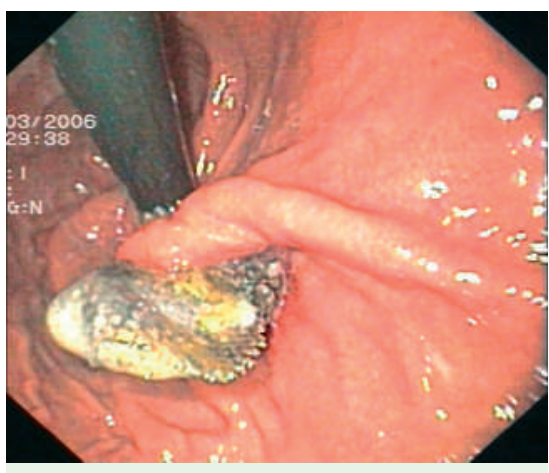

Fig. 1 The mesh eroded into the gastroesophageal junction.

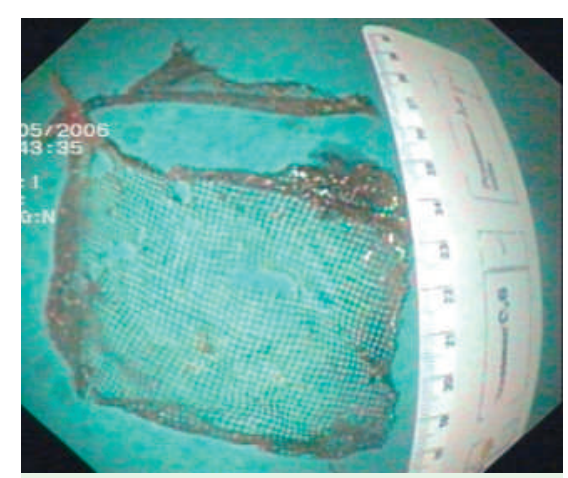

Fig. 2 The mesh after removal.

A 57-year-old man was treated for recurrent paraesophageal hernia by means of laparoscopic hiatal reinforcement using a $12 \times 10-\mathrm{cm}$ titanium-covered polypropylene mesh. He began to experience nonspecific epigastric abdominal discomfort 10 months later. An upper endoscopy revealed the presence of mesh at the gastroesophageal junction ( $\bullet$ Fig. 1), which was then removed endoscopically, using grasping forceps ( $\mathbf{F i g . 2}$ ). Since the procedure, the patient has been free of symptoms, with no signs of reflux disease for 12 months at the time of writing.

According to the rationale of tension-free meshed hernia repair, the use of prosthetic materials for repair of the hiatus in large paraesophageal hernias is increasingly common. Prospective randomized trials have shown that the use of prosthetic materials for hiatal reinforcement results in a significantly lower rate of hernia recurrence [1].

It is known from the complications of inguinal and ventral hernia surgery [2] that the main argument against mesh placement at the hiatus is the risk of visceral erosion. Statistically, the risk of mesh erosion after prosthetic hiatal reinforcement is reported to be up to $2.3 \%$ [3]. It is postulated that mesh migration is prevented when the mesh placement is protected by the fundic wrap and is not in contact with the esophageal wall [4].

Endoscopic treatment is an effective as well as safe method for removal of an eroding mesh. The use of an open surgical method is not necessary as long as the eroded organ wall is still intact without evidence of any leak. In order to ensure tension-free repairs of large hiatal hernias, the use of prosthetic materials is necessary; however, in our opinion, hiatal repair using mesh should only be carried out where appropriate, because of the risk of erosion

Endoscopy_UCTN_Code_CCL_1AB_2AD_3AF

\section{B. Rumstadt ${ }^{1}$, G. Kähler ${ }^{2}$, O. Mickisch ${ }^{3}$,}

D. Schilling ${ }^{4}$

1 Department of Surgery, Diakonienkrankenhaus Mannheim, Germany

2 Department of Surgical Endoscopy, University of Mannheim, Germany

3 Gastroenterological Clinic, Wasserturm, Mannheim, Germany

4 Department of Gastroenterology, Diakonienkrankenhaus Mannheim, Germany

\section{References}

1 Granderath FA, Schweiger UM, Kamolz Tet al. Laparoscopic Nissen fundoplication with prosthetic hiatal closure reduces postoperative intrathoracic wrap herniation. Arch Surg 2005; 140: 40-48

2 Losanof JE, Richman BW, Jones JW. Enterocolocutaneous fistula: a late consequence of polypropylene mesh abdominal wall repair: case report and review of the literature. Hernia 2002; 6: 144-147

3 Targarona EM, Bendahan G, Balague C et al. Mesh in the hiatus. Arch Surg 2004; 139: $1286-1296$

4 Edelmann DS. Laparoscopic paraesophageal hernia repair with mesh. Surg Laparosc Endosc 1995; 5: $32-37$
Bibliography

DOI 10.1055/s-2007-995332

Endoscopy 2008; 40: E70

(c) Georg Thieme Verlag KG Stuttgart · New York . ISSN 0013-726X

\section{Corresponding author}

\section{B. Rumstadt, MD}

Diakoniekrankenhaus Mannheim

Chirurgische Klinik

Speyerer Strasse 91 - 93

68163 Mannheim

Fax: +49-621-81023010

b.rumstadt@diako-ma.de 